\title{
Zanubrutinib monotherapy in relapsed/ refractory mantle cell lymphoma: a pooled analysis of two clinical trials
}

\author{
Keshu Zhou', Dehui Zou², Jianfeng Zhou' ${ }^{3}$, Jianda Hu' ${ }^{4}$, Haiyan Yang ${ }^{5}$, Huilai Zhang ${ }^{6}$, Jie Ji ${ }^{7}$, Wei Xu', \\ Jie Jin ${ }^{9}$, Fangfang Lv ${ }^{10}$, Ru Feng ${ }^{11}$, Sujun Gao ${ }^{12}$, Daobin Zhou ${ }^{13}$, Constantine S. Tam ${ }^{14}$, David Simpson ${ }^{15}$, \\ Michael Wang ${ }^{16}$, Tycel J. Phillips ${ }^{17}$, Stephen Opat ${ }^{18}$, Zhiyue Huang ${ }^{19}$, Huafei Lu ${ }^{19}$, Yuqin Song ${ }^{20^{*}}$ and \\ Yongping Song ${ }^{1 *}$
}

\begin{abstract}
Mantle cell lymphoma (MCL) is a mature B-cell neoplasm with a high initial response rate followed almost invariably by relapse. Here we report the pooled data from 2 studies, BGB-3111-AU-003 and BGB-3111-206, to explore the efficacy of zanubrutinib monotherapy in relapsed/refractory (R/R) MCL. A total of 112 patients were included. Median follow-up durations were 24.7 and 24.9 months for BGB-3111-AU-003 and BGB-3111-206, respectively. Overall response rate (ORR) and complete response (CR) rate were $84.8 \%$ and $62.5 \%$, and median duration of response, progression-free survival (PFS) and overall survival (OS) were 24.9, 25.8 and 38.2 months, respectively. After weighting, the PFS (median: NE vs. 21.1 months, $P=0.235$ ) and $O S$ (median: NE vs. 38.2 months, $P=0.057$ ) were similar but numerically better in the second-line than later-line group. Zanubrutinib was well-tolerated with treatment discontinuation and dose reduction for adverse events in $12.5 \%$ and $2.7 \%$ of patients, respectively. Hypertension, major hemorrhage and atrial fibrillation/flutter rates were $11.6 \%, 5.4 \%$ and $1.8 \%$, respectively. Zanubrutinib is efficacious in R/R MCL, with a favorable safety profile.
\end{abstract}

Keywords: Complete response rate, Mantle cell lymphoma, Progression-free survival, Second-line therapy, Zanubrutinib

To the editor,

MCL is a rare, B-cell non-Hodgkin lymphoma with highly heterogeneous clinical presentation and aggressiveness [1-3]. Before the use of Bruton's tyrosine kinase (BTK) inhibitors, therapeutic options for patients with $\mathrm{R} / \mathrm{R}$ MCL were limited, and their outcomes were generally poor [4-6]. Zanubrutinib is a next-generation, highly specific and potent BTK inhibitor [3, 7].Based

\footnotetext{
*Correspondence: songyuqin622@163.com; songyongping001@126.com ${ }^{1}$ Affiliated Cancer Hospital of Zhengzhou University, Henan Cancer Hospital, Zhengzhou 450003, China

${ }^{20}$ Department of Lymphoma, Peking University Cancer Hospital and Institute, Beijing 100142, China

Full list of author information is available at the end of the article
}

on two phase I/II studies (BGB-3111-206 and BGB3111-AU-003) [8, 9], Zanubrutinib was approved in 2019 by the US Food \& Drug Administration for the treatment of adult patients with MCL who have received at least one prior therapy.

For this analysis, the patient-level data from BGB-3111206 and BGB-3111-AU-003 were pooled to further characterize the efficacy profile of zanubrutinib monotherapy in R/R MCL.

A total of 112 patients were included, with 33 from BGB-3111-AU-003 and 79 from BGB-3111-206. The median duration of follow-up in BGB-3111-AU-003 and BGB-3111-206 was 24.7 and 24.9 months, respectively. Across the overall population, the median duration of original author(s) and the source, provide a link to the Creative Commons licence, and indicate if changes were made. The images or other third party material in this article are included in the article's Creative Commons licence, unless indicated otherwise in a credit line to the material. If material is not included in the article's Creative Commons licence and your intended use is not permitted by statutory regulation or exceeds the permitted use, you will need to obtain permission directly from the copyright holder. To view a copy of this licence, visit http://creativecommons.org/licenses/by/4.0/. The Creative Commons Public Domain Dedication waiver (http://creativeco mmons.org/publicdomain/zero/1.0/) applies to the data made available in this article, unless otherwise stated in a credit line to the data. 
follow-up was 24.9 months, and the duration of treatment was 20.4 months. Most of the patients had Stage III or IV disease (91\%) and low to intermediate MCL International Prognostic Index (MIPI) risk scores (79\%). There were $8 \%$ with bulky disease and $13 \%$ with blastoid variant (Table 1).

Before weighting, there were 41 patients in the second-line group and 71 patients in the later-line group. The second-line group had higher age, body mass index (BMI) and a higher percentage of patients with high MIPI risk scores, and lower percentages of patients with extra nodal disease and blastoid subtype compared with the later-line group. After weighting, all baseline covariates were balanced between the second- and later-line groups (Additional file 1: Table S1).The effective sample sizes were 27 in the second-line group and 59 in the laterline group, with median treatment durations of 22 and 18.8 months, respectively.

Prior treatment regimens included cyclophosphamide/vincristine/doxorubicin/dexamethasone (hyperCVAD) or hyper-CVAD-like regimens (9\% and $19 \%$ ), lenalidomide ( 0 and $14 \%)$, bortezomib (1\% and $10 \%)$ and autologous stem cell transplantation ( $2 \%$ and $10 \%)$ in second- and later-line therapy groups, respectively. The percentage of patients who received prior bendamustine was low in both groups (4\% in second-line and $5 \%$ in laterline; Additional file 1: Table S2).

In BGB-3111-AU-003, the ORR was $84.9 \%$, and the CR rate was $24.2 \%$; the median PFS was 16 months, and the median OS was 25.8 months. In BGB-3111-206, the ORR was $84.8 \%$, and the CR rate was $78.5 \%$; the median PFS was 25.8 months, and the median OS was not reached (Additional file 1: Figure S1). The difference in CR rates between the two trials might be due to the different imaging strategies (Additional file 1) and poorer patients' condition in BGB-3111-AU-003 (Table 1). In the pooled population, the ORR and the CR rate were $84.8 \%$ (95\% CI: 76.8-90.9\%) and 62.5\% (95\% CI: 52.8-71.5\%); the median duration of response(DOR), PFS and OS were 24.9 (95\% CI: 19.5-not estimable [NE]), 25.8 (95\% CI: 16.8-NE) and 38.2 (95\% CI: 29.3-NE) months, respectively (Additional file 1: Figure S2).

After weighting, the ORR (89.4 vs. $85.5 \%$, adjusted $\mathrm{OR}=1.5 ; P=0.538$ ), DOR (median: NE vs. 23.1 months, adjusted $\mathrm{HR}=0.743 ; P=0.436$ ), PFS (median: NE vs. 21.1 months, adjusted $\mathrm{HR}=0.679 ; P=0.235$ ) and $\mathrm{OS}$ (median: NE vs. 38.2 months, adjusted $\mathrm{HR}=0.449$; $P=0.057)$ were similar but numerically better in the second-line than later-line group (Additional file 1: Figure S3).

Table 1 Baseline covariates in two trials

\begin{tabular}{|c|c|c|c|}
\hline & $\begin{array}{l}\text { All } \\
(n=112)\end{array}$ & $\begin{array}{l}\text { BGB-3111-AU-003 } \\
(n=33)\end{array}$ & $\begin{array}{l}\text { BGB-3111-206 } \\
(n=79)\end{array}$ \\
\hline \multicolumn{4}{|l|}{ Age } \\
\hline Mean (SD) & $61.55(9.97)$ & $69.12(9.93)$ & $58.39(8.16)$ \\
\hline Median & 62 & 70 & 60 \\
\hline Sex, male & $86(77 \%)$ & $25(76 \%)$ & $61(77 \%)$ \\
\hline BMI, mean (SD) & $24.94(4.18)$ & $27.88(4.82)$ & $23.72(3.19)$ \\
\hline ECOG PS, $>1$ & $6(5 \%)$ & $3(9 \%)$ & $3(4 \%)$ \\
\hline \multicolumn{4}{|l|}{ Disease stage } \\
\hline 1 & $3(3 \%)$ & $2(6 \%)$ & $1(1 \%)$ \\
\hline$\|$ & $7(6 \%)$ & 0 & $7(9 \%)$ \\
\hline III & $14(13 \%)$ & $1(3 \%)$ & $13(16 \%)$ \\
\hline IV & $88(79 \%)$ & $30(91 \%)$ & $58(73 \%)$ \\
\hline Number of prior lines of therapy, median & 2 & 1 & 2 \\
\hline Blastoid variant & $14(13 \%)$ & $2(6 \%)$ & $12(15 \%)$ \\
\hline \multicolumn{4}{|l|}{ MIPI } \\
\hline High risk & $24(21 \%)$ & $15(45 \%)$ & $9(11 \%)$ \\
\hline Intermediate risk & $33(29 \%)$ & $10(30 \%)$ & $23(29 \%)$ \\
\hline Low risk & $55(49 \%)$ & $8(24 \%)$ & $47(59 \%)$ \\
\hline Bulky & $9(8 \%)$ & $3(9 \%)$ & $6(8 \%)$ \\
\hline Extra-nodal & $67(60 \%)$ & $9(27 \%)$ & $58(73 \%)$ \\
\hline Bone marrow involvement & $58(52 \%)$ & $21(64 \%)$ & $37(47 \%)$ \\
\hline
\end{tabular}


Table 2 Extent of exposure and adverse events before and after weighting

\begin{tabular}{|c|c|c|c|c|c|c|}
\hline & \multicolumn{3}{|c|}{ Before weighting } & \multicolumn{3}{|c|}{ After weighting } \\
\hline & $\begin{array}{l}\text { Second-line } \\
\text { therapy } \\
(n=41)\end{array}$ & $\begin{array}{l}\text { Later-line } \\
\text { therapy } \\
(n=71)\end{array}$ & All $(n=112)$ & $\begin{array}{l}\text { Second-line } \\
\text { therapy } \\
(E S S=27)\end{array}$ & $\begin{array}{l}\text { Later-line } \\
\text { therapy } \\
(\mathrm{ESS}=59)\end{array}$ & All $(E S S=86)$ \\
\hline \multicolumn{7}{|l|}{ Extent of exposure } \\
\hline Median duration of treatment (months) & 20.53 & 20.27 & 20.4 & 22.0 & 18.8 & 19.9 \\
\hline Dose reduction due to $A E, \%$ & 2.4 & 2.8 & 2.7 & 1.8 & 2.4 & 2.2 \\
\hline Dose interruption due to $A E, \%$ & 4.9 & 14.1 & 10.7 & 3.7 & 11.2 & 8.5 \\
\hline Dose modification due to $\mathrm{AE}, \%$ & 7.3 & 14.1 & 11.6 & 5.5 & 11.2 & 9.2 \\
\hline Treatment discontinuation, \% & 51.2 & 56.3 & 54.5 & 46.9 & 58.3 & 54.3 \\
\hline Due to $A E, \%$ & 17.1 & 9.9 & 12.5 & 10.6 & 11.0 & 10.9 \\
\hline Due to $P D, \%$ & 34.1 & 43.7 & 40.2 & 36.4 & 42.9 & 40.6 \\
\hline Due to withdrawal, \% & 0.0 & 1.4 & 0.9 & 0.0 & 3.3 & 2.1 \\
\hline Due to investigators, $\%$ & 0.0 & 1.4 & 0.9 & 0.0 & 1.1 & 0.7 \\
\hline \multicolumn{7}{|l|}{ Adverse events } \\
\hline At least one $A E, \%$ & 95.1 & 97.2 & 96.4 & 95.4 & 98.2 & 97.2 \\
\hline At least one grade $\geq 3 A E, \%$ & 51.2 & 50.7 & 50.9 & 47.3 & 48.1 & 47.8 \\
\hline At least one AE leading to death, $\%$ & 4.9 & 8.5 & 7.1 & 3.1 & 7.9 & 6.2 \\
\hline At least one $S A E, \%$ & 41.5 & 29.6 & 33.9 & 38.3 & 28.1 & 31.7 \\
\hline At least one AESI, \% & 78.1 & 91.6 & 86.6 & 82.5 & 91.3 & 88.2 \\
\hline Hypertension ${ }^{a}, \%$ & 12.2 & 11.3 & 11.6 & 12.2 & 12.7 & 12.5 \\
\hline Major hemorrhage ${ }^{b}, \%$ & 2.4 & 7.0 & 5.4 & 1.0 & 6.1 & 4.3 \\
\hline Atrial fibrillation/flutter & 2.4 & 1.4 & 1.8 & 1.0 & 2.5 & 2.0 \\
\hline Grade $\geq 3$ atrial fibrillation/flutter & 0 & 1.4 & 0.9 & 0 & 2.5 & 1.6 \\
\hline
\end{tabular}

$A E$ adverse events, $A E S /$ adverse events of special interest, $P D$ progressive diseases, $S A E$ serious $A E, E S S$ effective sample size

${ }^{a}$ Includes preferred terms hypertension and blood pressure increased

${ }^{\mathrm{b}}$ Includes preferred term renal haematoma

In the original population, the rate of treatment discontinuation due to disease progression was $40.2 \%$ and due to AEs was $12.5 \%$. Most patients (96.4\%) experienced at least one $\mathrm{AE}$, and $50.9 \%$ experienced at least one grade $\geq 3$ AE. Serious AEs (SAEs) occurred in $33.9 \%$ of patients and $\mathrm{AE}$ leading to death occurred in $7.1 \%$ (congestive heart failure, $n=1$; general disorders, $n=2$; pneumonia, $\mathrm{n}=2$; road traffic accident, $\mathrm{n}=1$; hemorrhagic stroke, $\mathrm{n}=1$; ischemic stroke, $\mathrm{n}=1$ ). The most focused $\mathrm{AE}$ of special interest (AESI) were hypertension (11.6\%), major hemorrhage (5.4\%) and atrial fibrillation/flutter (1.8\%). The incidence of grade $\geq 3$ atrial fibrillation was $0.89 \%$ (Table 2). Detailed information of AEs was presented in Additional file 1: Table S3.

In conclusion, zanubrutinib is an effective and well-tolerated therapeutic option for R/R MCL. Early treatment with zanubrutinib tends to have better survival profiles.

\section{Abbreviations}

AEs: Adverse events; AESI: AE of special interest; BMI: Body mass index; BTK: Bruton's tyrosine kinase; CR: Complete response; DOR: Duration of response; ECOG: Eastern Cooperative Oncology Group; EGFR: Epidermal growth factor receptor; FDA: Food \& Drug Administration; IPSW: Inverse propensity score weighting; ITK: Interleukin-inducible tyrosine kinase; JAK3: Janus kinase 3; MCL: Mantle cell lymphoma; MIPI: MCL International Prognostic Index; NE: Not estimable; ORR: Overall response rate; OS: Overall survival; PFS: Progressionfree survival; R/R: Relapsed/refractory; SAEs: Serious adverse events.

\section{Supplementary Information}

The online version contains supplementary material available at https://doi. org/10.1186/s13045-021-01174-3.

Additional file 1. Supplementary methods. Table S1. Baseline covariates before and after weighting. Table $\mathbf{S 2}$. Prior medication uses after weighting. Table S3. Treatment emergent AEs (any grade, grade 3 or higher). Figure S1. Outcomes of patients with R/R MCL treated with zanubrutinib in the BGB-3111-AU-003 and BGB-3111-206 trial. (A) DOR in the BGB-3111-AU-003. (B) PFSin the BGB-3111-AU-003. (C) OS in the BGB-3111-AU-003. (D) DOR in the BGB-3111-206. (E) PFS in the BGB-3111206. (F) OS in the BGB-3111-206. Figure S2. Outcomes of patients with R/R $M C L$ treated with zanubrutinib. (A) DOR. (B) PFS. (C) OS. Figure S3. Outcomes of patients with R/R MCL treated with zanubrutinibas second- versus later-line therapy. (A) DOR before weighting. (B) PFS before weighting. (C) OS before weighting. (D) DOR after weighting. (E) PFS after weighting. (F) OS after weighting.

Acknowledgements

We would like to thank all of the investigators, the coordinators at each of the clinical sites, and especially the patients who participated in this trial, as well as their families. 


\section{Authors' contributions}

All authors interpreted the study data and contributed to preparation of the manuscript. Zhiyue Huang analyzed the data. All authors reviewed the results and approved the final version of the manuscript. All authors read and approved the final manuscript.

\section{Funding}

This study was sponsored by BeiGene.

\section{Availability of data and materials}

The datasets used and/or analyzed during the current study are available from the corresponding author on reasonable request.

\section{Declarations}

Ethics approval and consent to participate

All methods were performed in accordance with the relevant guidelines and regulations.

\section{Consent for publication}

Not applicable.

\section{Competing interests}

The authors declare that they have no competing interests.

\section{Author details}

${ }^{1}$ Affiliated Cancer Hospital of Zhengzhou University, Henan Cancer Hospital, Zhengzhou 450003, China. ${ }^{2}$ Institute of Hematology and Blood Diseases Hospital, Chinese Academy of Medical Sciences and Peking Union Medical College, Tianjin 300020, China. ${ }^{3}$ Tongji Hospital, Tongji Medical College, Wuhan 430032, China. ${ }^{4}$ Fujian Medical University Union Hospital, Fuzhou 35000, China. ${ }^{5}$ Zhejiang Cancer Hospital, Hangzhou 310000, China. ${ }^{6}$ Tianjin Medical University Cancer Institute and Hospital, Tianjin 300060, China. ${ }^{7}$ West China Hospital of Sichuan University, Chengdu 610041, China ${ }^{8}$ The First Affiliated Hospital of Nanjing Medical University, Jiangsu Province Hospital, Nanjing 210029, China. ${ }^{9}$ The First Affiliated Hospital, Zhejiang University College of Medicine, Hangzhou 310003, China. ${ }^{10}$ Fudan University Shanghai Cancer Center, Shanghai 200032, China. ${ }^{11}$ Nanfang Hospital of Southern Medical University, Guangzhou 510515, China. ${ }^{12}$ The First Hospital of Jilin University, Changchun 130031, China. ${ }^{13}$ Peking Union Medical College Hospital, Chinese Academy of Medical Sciences and Peking Union Medical College, Beijing 100730, China. ${ }^{14}$ Peter MacCallum Cancer Centre, St. Vincent's Hospital, University of Melbourne, Melbourne, VIC 3065, Australia. ${ }^{15}$ North Shore Hospital, Auckland 2065, New Zealand. ${ }^{16}$ The University of Texas MD Anderson Cancer Center, Houston, TX 78701, USA. ${ }^{17}$ University of Michigan, Ann Arbor, MI 48109, USA. ${ }^{18}$ Monash Health, Monash University, Clayton,
VIC 3800, Australia. ${ }^{19}$ BeiGene (Beijing) Co., Ltd, Beijing 102206, China. ${ }^{20}$ Department of Lymphoma, Peking University Cancer Hospital and Institute, Beijing 100142, China.

Received: 7 August 2021 Accepted: 22 September 2021 Published online: 14 October 2021

\section{References}

1. Vose JM. Mantle cell lymphoma: 2015 update on diagnosis, risk-stratification, and clinical management. Am J Hematol. 2015;90:739-45.

2. Dreyling M, Geisler C, Hermine O, Kluin-Nelemans HC, Le Gouill S, Rule S, et al. Newly diagnosed and relapsed mantle cell lymphoma: ESMO Clinical Practice Guidelines for diagnosis, treatment and follow-up. Ann Oncol. 2014;25 Suppl 3:iii83-92.

3. Li G, Liu X, Chen X. Simultaneous development of zanubrutinib in the USA and China. Nat Rev Clin Oncol. 2020;17:589-90.

4. Goy A, Bernstein SH, Kahl BS, Djulbegovic B, Robertson MJ, de Vos S, et al. Bortezomib in patients with relapsed or refractory mantle cell lymphoma: updated time-to-event analyses of the multicenter phase 2 PINNACLE study. Ann Oncol. 2009;20:520-5.

5. Goy A, Sinha R, Williams ME, Kalayoglu Besisik S, Drach J, Ramchandren R, et al. Single-agent lenalidomide in patients with mantle-cell lymphoma who relapsed or progressed after or were refractory to bortezomib: phase II MCL-001 (EMERGE) study. J Clin Oncol. 2013;31:3688-95.

6. Hess G, Herbrecht R, Romaguera J, Verhoef G, Crump M, Gisselbrecht C, et al. Phase III study to evaluate temsirolimus compared with investigator's choice therapy for the treatment of relapsed or refractory mantle cell lymphoma. J Clin Oncol. 2009;27:3822-9.

7. Guo Y, Liu Y, Hu N, Yu D, Zhou C, Shi G, et al. Discovery of Zanubrutinib (BGB-3111), a Novel, Potent, and Selective Covalent Inhibitor of Bruton's Tyrosine Kinase. J Med Chem. 2019;62:7923-40.

8. Tam CS, Trotman J, Opat S, Burger JA, Cull G, Gottlieb D, et al. Phase 1 study of the selective BTK inhibitor zanubrutinib in B-cell malignancies and safety and efficacy evaluation in CLL. Blood. 2019;134:851-9.

9. Song Y, Zhou K, Zou D, Zhou J, Hu J, Yang H, et al. Treatment of patients with relapsed or refractory mantle-cell lymphoma with Zanubrutinib, a selective inhibitor of Bruton's tyrosine kinase. Clin Cancer Res. 2020:26:4216-24

\section{Publisher's Note}

Springer Nature remains neutral with regard to jurisdictional claims in published maps and institutional affiliations.
Ready to submit your research? Choose BMC and benefit from:

- fast, convenient online submission

- thorough peer review by experienced researchers in your field

- rapid publication on acceptance

- support for research data, including large and complex data types

- gold Open Access which fosters wider collaboration and increased citations

- maximum visibility for your research: over 100M website views per year

At BMC, research is always in progress.

Learn more biomedcentral.com/submissions 